\title{
O uso da Loop Station em performance musical: implicações
}

\section{e exigências interpretativas}

\author{
Alexsander Jorge Duarte \\ INET-md - Instituto de Etnomusicologia, centro de estudos em música e dança | Portugal
}

Resumo: O objetivo deste artigo é discutir sobre as possibilidades de uso da Loop Station em performances musicais e suas implicaçôes. $\mathrm{O}$ texto centra-se na criação e performance de um arranjo/exercício que consiste numa colagem das obras musicais Beat 70 (Pat Metheny) e Asa branca (Luiz Gonzaga/Humberto Teixeira) e utiliza como setup: flauta transversal, Loop Station Boss RC-30, pedal Guitar Processor GP-10 e Footswitch. Busca-se, portanto, abordar o processo de preparação, elaboração e performance, descrevendo aspetos importantes como: configuração de parâmetros de efeitos, exigências interpretativas com relação ao movimento do corpo no controle de pedais e critérios para notação musical. Este arranjo/exercício foi desenvolvido com fins didáticos, onde a componente tecnológica é significativamente simples, visto ser direcionado para pessoas com pouca ou nenhuma experiência com pedais de efeitos e tem sido usado em workshops realizados em escolas de música, festivais, conferência e outros tipos de encontro.

Palavras-chave: Loop station, pedais de efeito, notação musical, gesto intelectual, didática.

\begin{abstract}
The purpose of this article is to discuss the possibilities of using a Loop Station in musical performances and their implications. The text focuses on the creation and performance of an arrangement/exercise consisting of a collage of the songs Beat 70 (Pat Metheny) and Asa Branca (Luiz Gonzaga/Humberto Teixeira) and the setup comprises: Transverse Flute, Boss RC-30 Loop Station, Guitar Processor GP-10 pedal and Footswitch. The article also aims to approach the process of preparation, elaboration and performance of the arrangement, describing important aspects such as: the configuration of effects parameters, interpretative requirements regarding foot movement in pedal control and criteria for score transcription. This arrangement/exercise was developed for didactic purposes, where the technological component is significantly simple, since it is aimed at people with little or no experience with effects pedals and has been used in workshops held at music schools, festivals, conferences and other types of encounters.
\end{abstract}

Keywords: Loop station, effect pedals, score transcription, intellectual gesture, didacticism. 

este artigo $^{1}$ apresento um arranjo/exercício composto para flauta transversal, Loop Station e pedal de efeitos que tem como propósito servir como exercício àqueles que não tem familiaridade com essas ferramentas tecnológicas (por isso chamá-lo de “arranjo-exercício”) ${ }^{2}$. Apresentarei o processo de análise e elaboração deste, programação de pedais e performance. Trata-se de uma "colagem" de Beat 70 (Pat Metheny) e Asa branca (Luiz Gonzaga/Humberto Teixeira) e resulta de um exercício de análise da performance do flautista italiano Michele Gori (que é um arranjo de Beat 70 para flauta transversal em Dó, flauta contralto e flauta baixo com Loop Station e efeitos com o software Guitar Rig) ${ }^{3}$.

Para chegar a esse resultado a metodologia adotada passou pelas seguintes etapas que formam o corpo desse texto: 1) breve explanação sobre a Loop Station (LS) e questóes técnicas e conceptuais; 2) reflexão sobre soluções e decisões de notação de partitura e postura interpretativa necessária para a performance do arranjo/exercício; e 3) análise deste e bem como da performance ${ }^{4}$, o que possibilitou contextualizar o setup e identificar questôes composicionais e interpretativas bem como as programações dos efeitos e parâmetros no pedal de modulação. Por fim, apresento as reflexões e considerações finais.

A considerar a escassa bibliografia acadêmica sobre performances musicais com uso da LS, sobretudo no que diz respeito à componente prática e didática, este trabalho busca oferecer como contributo: 1) reflexão sobre modelo de notação para arranjos e composições com uso de LS; e 2) exemplificação de construção de arranjo ou composição com uso da LS. Entendo que a descrição e análise sobre o processo composicional e interpretativo do arranjo/exercício também são

\footnotetext{
${ }^{1}$ Este artigo - resultado de uma comunicação apresentada no Congresso Performa'17/V Congresso Abrapem em junho de 2017 em São João del Rey, Minas Gerais/BR - é parte de uma pesquisa de pós-doutoramento em desenvolvimento que tem como foco abordar um tipo de prática performativa musical designada por Live Looping (LL).

${ }^{2}$ Este trabalho se inscreve no quadro de uma atividade desenvolvida no LoopLab - Laboratório de práticas musicais que se utilizam da tecnologia Live Looping (LL) - e é desenvolvido na Universidade de Aveiro, aberto à comunidade acadêmica e não acadêmica. Nesse espaço, de forma dialógica e coletiva, discute-se questóes estruturais de composiçóes musicais com LL, configuraçóes tecnológicas e postura interpretativa. Como os participantes do Laboratório têm sido, na maioria, performers sem experiência de práticas com dispositivos eletrônicos, este trabalho tem apontado para atender este perfil de interessados. Metodologicamente, entende-se que este modelo de pesquisa científica, designado por "práticas de investigação partilhada" (SARDO, 2017: 231), privilegia uma maior democratização, quer da construção, quer do acesso ao conhecimento cientificamente produzido.

${ }^{3}$ Disponível em: < https://www.youtube.com/watch?v=0biR8Pad0FQ $>$ a partir dos 3:40. Acesso em: 03 mar. 2019.

${ }^{4}$ Como esta performance foi elaborada com propósito de demonstrar o uso da Loop Station numa Comunicação em Congresso, buscou-se priorizar: 1) uma performance de curta duração (máximo de 2 minutos); 2) portabilidade (mínimo possível de equipamentos para transporte).
} 
contribuições importantes dessa pesquisa no sentido de auxiliar e motivar novas composições, performances e pesquisas sobre esta temática.

Por fim, este artigo tem como objetivo geral contribuir para suprir uma lacuna no que se refere à literatura acadêmica sobre performance musical com uso da LS. Assim, o texto é direcionado, sobretudo, àqueles que se encontram em fase inicial de contato com esta ferramenta $\mathrm{e}$ busca provocar o interesse para diferentes perspectivas de abordagens performativas para instrumentos de sopro de forma a se explorar pesquisas de timbres, processos composicionais com uso de LS e metodologias de estudos. Portanto, trata-se de um estudo que propositalmente aborda uma tecnologia significativamente simples, porém sobre a qual pouco ou quase nada tem sido publicado em revistas científicas.

\section{Problematização e metodologia adotada}

Segundo Eduardo Paiva (2012, p. 99), “as diversas tecnologias ligadas aos processos de gravação sonora, passaram, a partir dos anos 60, a ser compreendidos como 'meios expressivos' capazes de permitir o surgimento de novas linguagens e procedimentos ligados a criação musical” (PAIVA, 2012, p. 99). O autor faz uma leitura do percurso histórico da indústria fonográfica e a evolução dos recursos tecnológicos de suporte, do vinil ao $\mathrm{mp} 3$, e a atual realidade da “deslocalização" física de suporte, com arquivos digitais existentes "nas nuvens”. Durante sua explanação, ao contextualizar a ruptura entre a performance ao vivo e a produção do estúdio nos anos 1960 e 1970 (citando trabalhos emblemáticos como dos Beatles e Pink Floyd, tendo casos de discos que jamais foram reproduzidos ao vivo), o autor defende a ideia de que o estúdio pode ser visto como um meio expressivo ou mesmo um novo instrumento para o artista. Neste sentido, a LS entra atualmente como um recurso similar a um "estúdio portátil”, não somente no sentido de gravar e reproduzir, mas como um recurso de manipulação do material sonoro que permite ao performer buscar diferentes possibilidades de expressão musical.

Neste sentido, este trabalho procura abordar a LS como um "meio expressivo" e perceber: como se dá a utilização desta ferramenta? É usada como um complemento ou como elemento central na performance? É imprescindível? Por que utilizar a LS e não um playback ou sampler? A 
LS é uma ferramenta ampliadora ou limitadora de possibilidades?

Entendo que estas questóes são pertinentes visto que uso da LS tem se tornado muito comum, sobretudo por performers no contexto da música "popular" ou, de forma genérica, do universo da “canção”, numa perspectiva estética comumente chamada de one man band, onde há a construção de uma malha sonora que simula uma banda (com linhas de baixo, sessóes ritmos e acordes) servindo como uma base para solos (vocais ou instrumentais) ou sessóes de improviso. Isso pode ser verificado em diversos canais do youtube, por exemplo, além de performances em distintos contextos, desde bares a festivais de música. Exemplos de performers conhecidos no cenário internacional que usam LS são: Dub FX, Reggie Watts, Ed Sheeran, Matthew Schoening, Josie Charlwood, Kewahi, Gavin Castleton, Andrew Bird, Yellow Ostrich, Grace McLean, Jarle Bernhoft e até mesmo Richard Bona.

Como resultado desta reflexão, no sentido de explorar diferentes alternativas para o uso da LS, foi criado o LoopLab - Laboratório de Live Looping na Universidade de Aveiro - que busca possibilidades de uso desta ferramenta na elaboração de novas composiçóes e arranjos. Assim, emerge-se outras questóes que serão aqui abordadas: o que implica o uso da LS do ponto de vista do performer? Como abordar o corpo de forma a integrar os movimentos à performance criando sinergia? Com quais dificuldades e desafios o performer pode se confrontar?

A abordagem metodológica utilizada neste trabalho foi baseada no diálogo entre os participantes do Laboratório, no uso da autoetnografia, diálogo virtual (via e-mail) com o flautista Michele Gori (cuja performance foi adotada como ponto de partida e objetivo do arranjo/exercício a ser desenvolvido), e análise do mesmo e configuraçôes dos dispositivos eletrônicos.

Do ponto do enquadramento teórico, o conceito de "gesto intelectual” (CHAIB, 2012, p. 97) tem se mostrado como significativa ferramenta que, aplicada às situaçóes acima descritas, oferecem resultados práticos que orientam o perfomer diante do desafio das exigências interpretativas. $\mathrm{O}$ autor propóe perceber o gesto a partir de quatro fases - atenção, intenção, decisão e precisão - sobre o qual refletirei melhor na secção sobre a análise do processo de interpretação e sinergia do performer frente aos dispositivos controlados com os pés. 


\section{Loop Station}

Loops são sessões de áudio que se repetem. Os trabalhos minimalistas de Terry Riley e Steve Reich com fita magnética nas décadas de 1950 e 1960 já exploravam esse recurso. Por exemplo, na obra Come out de Steve Reich (1966), a frase "come out to show them” cria uma espécie de ostinato e sobre este vai-se aplicando efeitos, gerando granulaçóes do material musical. Entretanto, o que caracteriza a técnica conhecida como Live Looping (LL) é o fato de construir loops em tempo real em detrimento das performances onde os loops são pré-gravados e disparados no momento da performance.

Um artigo interessante foi publicado em 2017 (BARBOSA et al, 2017, p. 89), no qual é possível verificar uma análise de 101 ferramentas de LL - produzidas pelas indústrias de tecnologias ligadas à música, pelos estudos acadêmicos e projetistas independentes. Neste artigo percebe-se que, além dos pedais comercializados (LS e similares), há softwares que permitem programar uma "Loop Station virtual", como o Pure Data ou Max/MSP, ou mesmo o Ableton Live, que é muito usado (sobretudo por DJ's), onde é possível montar uma LS de 100 ou mais pistas usando-se um computador (que adicionalmente possibilitaria outras funções, como efeitos, automação etc.), ou mesmo um controlador MIDI. Samplers também podem ser utilizados como loops, porém este tema é demasiado amplo e sai do escopo deste trabalho. Aqui, o foco recai sobre o uso do pedal Loop Station e trata-se de uma tecnologia significativamente simples, destinada principalmente aos iniciantes neste tema.

A dimensão cíclica do loop tende a gerar repetição, o que pode incorrer em limitação por parte da criação musical. Neste sentido, alguns projetos de tecnologia mais avançada têm explorado outros horizontes no sentido de desenvolver ferramentas com maiores possibilidades de interação, com recursos de Inteligência Artificial, como é o caso do Projeto Reflexive Looper, desenvolvido pela equipe Flow Machines - um projeto de pesquisa e implantação que visa a aumentar a criatividade do artista na músicas

Os autores deste projeto criaram primeiramente uma versão focada na aplicação de sessões de improviso a partir da linguagem do jazz (PACHET et al, 2013, p. 2206). Recentemente,

\footnotetext{
${ }^{5}$ Disponível em: < https://www.flow-machines.com/history/projects/ai-musical/>. Acesso em: 04 mar. 2019.
} 
desenvolveram uma versão atualizada de forma a explorar outras linguagens:

Ao contrário de um pedal de loop comum, cada camada de som em Reflexive Looper é produzida por um agente inteligente de looping que se adapta ao músico e respeita determinadas restriçôes, usando otimização restrita. $\mathrm{Na}$ sua forma original, Reflexive Looper funcionou bem para improvisação de guitarra de jazz, mas não era adequado para músicas estruturadas como cançôes pop. Para trazer o sistema ao palco pop, revisitamos o sistema de interação, seguindo as orientações dos profissionais usuários que o testaram extensivamente. Descrevemos o revisitado sistema que pode acomodar pop e jazz. Graças à interação intuitiva do pedal e restrições de estrutura, o novo Reflexive Looper lida com música pop e já foi usado em vários em situaçôes de concertos ao vivo ${ }^{6}$. (MARCHINI et al, 2017, p. 01).

Entretanto, enquanto tecnologias como o Reflexive Looper não são acessíveis ao público em geral, os pedais comercializados convencionalmente são muito utilizados, precisamente por serem de fácil acesso.

\section{Critérios para notação musical}

Pelo fato de ser possível construir camadas de áudio em tempo real, um único performer pode reproduzir perante a audiência uma massa sonora mais densa, quer polifônica ou monofonicamente, que acusticamente seria impossível dadas as limitaçóes naturais dos instrumentos musicais. Assim, a performance pode criar um efeito de Ensemble ou de uma banda. Como há poucas partituras publicadas de obras com uso da LS, um dos problemas que nos surgiu foi determinar o critério ou modelo para transcrição.

Dentre os trabalhos publicados nessa linha, destacamos: 'Import/Export' - Suite for Global Junk, composta por Gabriel Prokofiev e editado em 20087; e Slipstream, composta por Florian Magnus Maier e editado em $2012^{8}$. No primeiro caso, o compositor utiliza materiais diversos (como garrafa de refrigerante e diferentes sacos plásticos) em interação com o pedal Loop Station modelo Boss RC-300. Apesar de se tratar de um repertório que se inscreve no âmbito da música

\footnotetext{
${ }^{6}$ Tradução livre do autor.

${ }^{7}$ Disponível em: https://gabrielprokofiev.bandcamp.com/album/import-export-gabriel-prokofiev-suite-for-globaljunk. Acesso em: 04/02/2019.

${ }^{8}$ Disponível em: https://www.ntcshop.nl/a-38576117/trombone-solo/slipstream-florian-magnus-maier/. Acesso em: 03/04/2019.
} 
“experimental” e explorar o uso de instrumentos não convencionais, o compositor adotou como critério de notação um padrão de escrita convencional, nos moldes da escrita clássica. No segundo caso, o compositor também adota uma escrita convencional, e oferece detalhes de configuração do pedal LS que, a exemplo de Prokofiev, também indicou o modelo Boss RC-300.

No caso deste trabalho, optou-se por utilizar uma estrutura de grade organizada da seguinte forma:

a) Solo: o primeiro pentagrama refere-se ao som tocado em tempo real, que pode ou não ser gravado pela LS;

b) Pista 01: composta por dois elementos: 1) uma linha para percussão (beatboxer); e 2) um pentagrama em Clave de Fá para linha do baixo;

c) Pista 02: composta por três elementos: 1) uma linha para percussão (colher de pedreiro); 2) um pentagrama em Clave de Sol para três vozes de flauta referentes aos acordes; 3) um pentagrama em Clave de Sol para duas vozes também referentes à harmonia (efeito de flauta contralto).

FIGURA 1 - Exemplo de opção de notação.

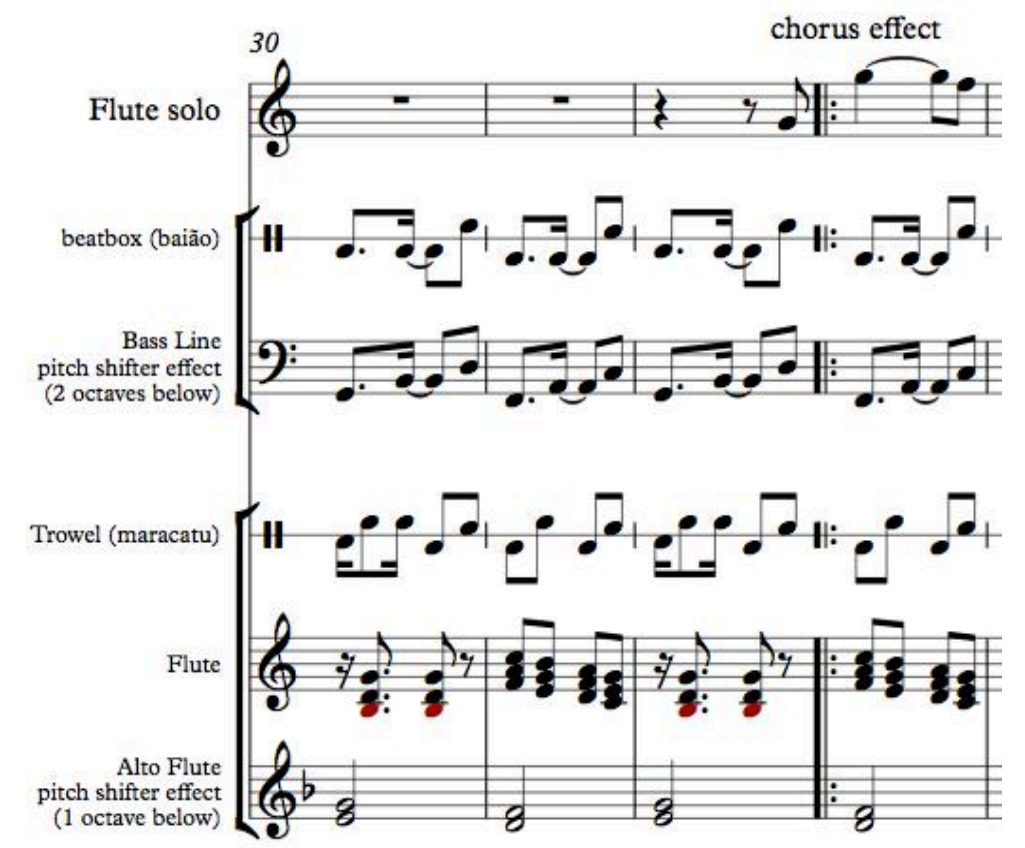

Fonte: transcrição do autor a partir de performance apresentada igualmente pelo autor, 2017. 
Entendemos que esta opção oferece visualmente uma percepção das vozes todas que estão a soar nas caixas amplificadas. Outro pormenor é que na partitura há as indicaçóes dos momentos de se carregar nos pedais de forma a clarificar ao intérprete os momentos de realização dos movimentos com os pés.

\section{Setup}

O setup (figura 2) utilizado neste trabalho consiste em: 1) Loop Station modelo Boss RC-30; 2) footswitch FS-5U para alternar as pistas da loop station; 3) pedal de efeitos de guitarra modelo GP10; 4) microfone dinâmico; 5) uma flauta transversal em Dó; 6) cabos e 7) caixas amplificadas.

FIGURA 2 - Setup de performance elaborada a propósito de demonstração no Congresso Performa'17 / V Congresso Abrapem.

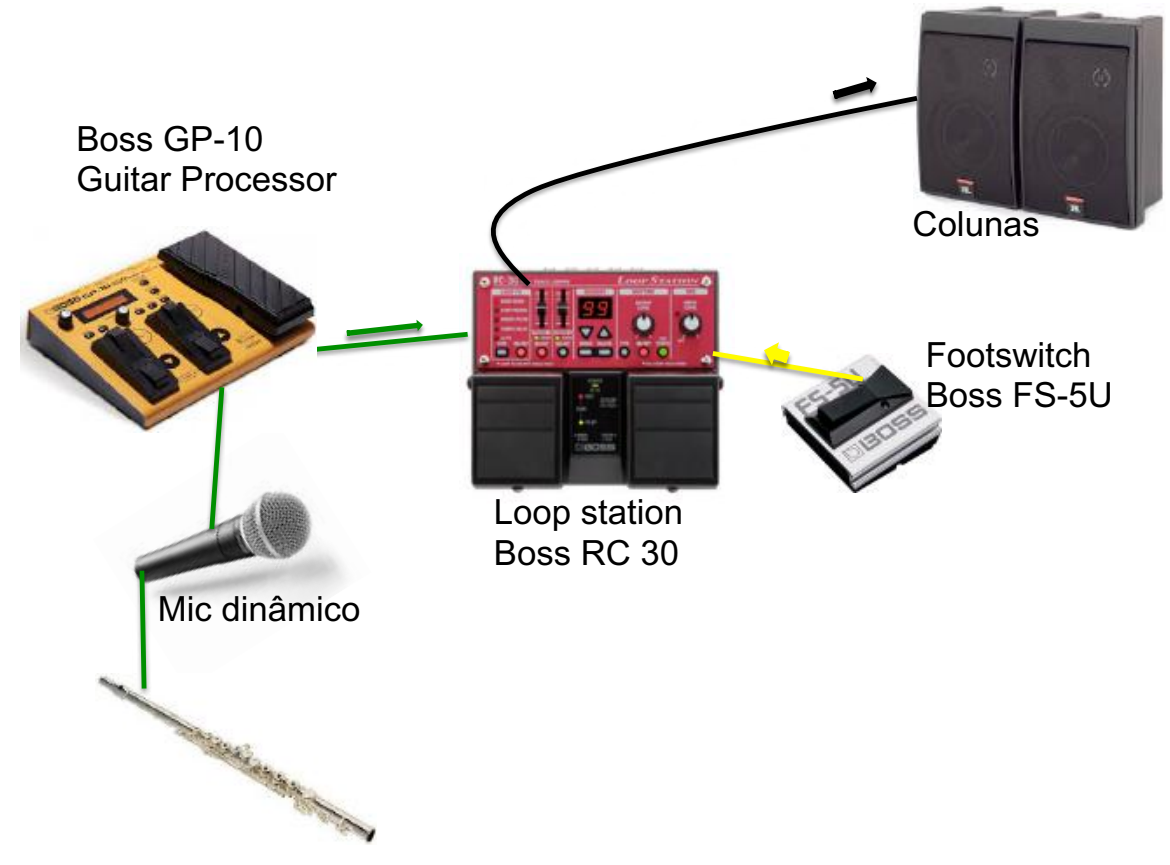

Fonte: Adaptação do autor a partir de imagens dos respectivos equipamentos na página da empresa: https://www.boss.info/us/

Os efeitos do pedal Boss GP-10 (processador de efeitos para guitarra elétrica) utilizados foram: 
TABELA 1 - Descrição dos efeitos (FX) utilizados pelo pedal GP-10.

\begin{tabular}{|c|c|}
\hline Efeitos (FX) - (GP-10) & Descriçãao \\
\hline barmonist & $\begin{array}{l}\text { Este efeito foi utilizado em } 3 \text { situações diferentes: } \\
\text { a) uma oitava abaixo para simular uma flauta contralto } \\
\text { (ou flauta baixo). Aqui a configuração dos parâmetros } \\
\text { effect level e direct level são decisivas para o resultado } \\
\text { desejado, ou seja, o direct level deve estar mutado e o } \\
\text { effect level ao máximo possível'. } \\
\text { b) duas oitavas abaixo para simular uma flauta } \\
\text { contrabaixo. A configuração dos parâmetros effect level e } \\
\text { direct level deu-se como na situação descrita } \\
\text { anteriormente. } \\
\text { c) uma quarta abaixo para solar a melodia de Asa branca } \\
\text { em duo. Neste caso, os parâmetros effect level e direct } \\
\text { level são igualmente calibrados para responderem no } \\
\text { output. }\end{array}$ \\
\hline rotary & $\begin{array}{l}\text { Reproduz o efeito como o som de um alto falante } \\
\text { rotativo, modulando o timbre da flauta (para solo da } \\
\text { melodia de Beat } 70)\end{array}$ \\
\hline delay/reverb & $\begin{array}{l}\text { Com propósito de criar espacialidade, estes efeitos foram } \\
\text { aplicados somente no momento dos solos. As vozes de } \\
\text { acompanhamento construídas nas pistas em overdubs } \\
\text { não tem aplicação destes efeitos para evitar excesso de } \\
\text { reverberação. }\end{array}$ \\
\hline
\end{tabular}

\section{Estrutura do arranjo/exercício}

Por que escolher este arranjo ou mesmo o trabalho de Michele Gori como referência? Isto deve-se em grande parte pelo fato de Michele Gori desenvolver um projeto intitulado Electric Flute no qual ele usa a família das flautas transversais juntamente com um Setup onde utiliza, além da LS, o software Guitar Rig para aplicar efeitos ao som dos instrumentos tais como chorus, delay, harmonizer, wah-wah, dentre outros ${ }^{10}$.

Minha intenção, durante o trabalho do Laboratório, foi replicar a estrutura do arranjo de Beat

\footnotetext{
${ }^{9}$ Apesar de na partitura o efeito estar descrito como "pitch shifter" (efeito este também disponível no pedal), a opção de se buscar o mesmo resultado, porém por outra via prende-se com a satisfação do resultado obtido. O timbre resultante obtido pela aplicação do harmonist agradou-me mais que pela aplicação do "pitch shifter". Entretanto, a opção por atribuir o nome do efeito como "pitch shifter" na partitura pode ser esclarecedor para aqueles que queiram perceber como se deu a configuração dos efeitos (outra opção seria descrever o efeito como "octaver", 1 ou 2 oitavas abaixo conforme o caso).

${ }^{10}$ Disponível em: <http://www.michelegori.it/projects.cfm?lingua=2 >. Acesso em: 03 abr. 2019.
} 
70 (de Pat Metheny) criado por Gori como forma de um exercício com propósitos didáticos, direcionado especialmente àqueles que não têm experiência com dispositivos eletrônicos, em particular a LS. Este arranjo/exercício tem sido utilizado em oficinas que tenho realizado em Portugal e no Brasil visto que muitos performers, no momento de experimentar a máquina, não tem nenhuma ideia do que se tocar. Neste sentido, o que compete à minha autoria diz respeito à opção rítmica dessa base, que é diferente daquela feita por Gori, e a inserção da melodia de Asa Branca com alteraçôes rítmicas e melódicas para adequar-se à base harmônica que a LS reproduz. Portanto, o arranjo do Gori é unicamente sobre a obra Beat 70 de Pat Metheny e a estrutura rítimica e melódica é fiel ao original de Pat Metheny. A ideia de introduzir a melodia de Asa Branca consta somente no arranjo/exercício elaborado por mim.

O exercício consistiu em: 1) audição da performance construída por Michele Gori; 2) transcrição da estrutura composicional; 3) criação a partir de estrutura similar; 4) notação do arranjo/exercício; 5) ensaio e identificação de exigências interpretativas.

A performance foi posteriormente reproduzida no estúdio do Departamento de Comunicação e Arte da Universidade de Aveiro em setembro de 2017 e está disponível em:

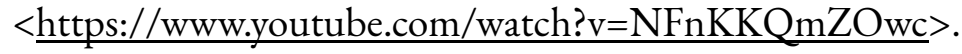

Vale salientar que na performance apresentada por Michele Gori, o flautista constrói a Estrutura Sonora Base em apenas um canal. A opção adotada no presente arranjo/exercício, que consiste em construir a base em duas pistas distintas, visa proporcionar uma variação de dinâmica e densidade mutando uma das pistas enquanto se executa a mudança de efeito no pedal de modulação.

De maneira ampla, este pode ser dividido em 5 “momentos":

Momento 01 - Criação de uma Estrutura Sonora Base

Momento 02 - Solo da melodia Beat 70 (com variação)

Momento 03 - Ponte

Momento 04 - Solo da melodia Asa Branca (com variação)

Momento 05 - Coda final 


\section{Momento 01}

Esta secção consiste numa base que assume função de playback, sobre a qual serão solados os respectivos temas musicais. Optou-se por adaptar a estrutura dos loops em grupos de 2 compassos binários. Pelo facto do modelo do pedal Loop Station Boss RC-30 apresentar limitações em termos de sincronismos e proporção de número de compassos entre as pistas, definir os loops com um número pequeno de compassos significa esperar menos tempo para que o ciclo se complete, o que resulta em uma atuação mais compacta no que se refere ao tempo despendido para a construção das pistas/overdubs.

Esta seção é formada por linha de baixo, harmonia (linhas melódicas a gerar os acordes) e base rítmica - subdivida em duas pistas na LS: Pista 01 e Pista 02. A base rítmica é constituída por dois diferentes ostinatos, gerando polirritmia. Optou-se por utilizar células rítmicas inspiradas na música tradicional brasileira (baião e maracatu), sendo o primeiro executado por beatbox na Pista 01 e o segundo por uma colher de pedreiro (trolha) na Pista 02.

FIGURA 3 - Detalhe para ostinatos em variaçóes de baião e maracatu.

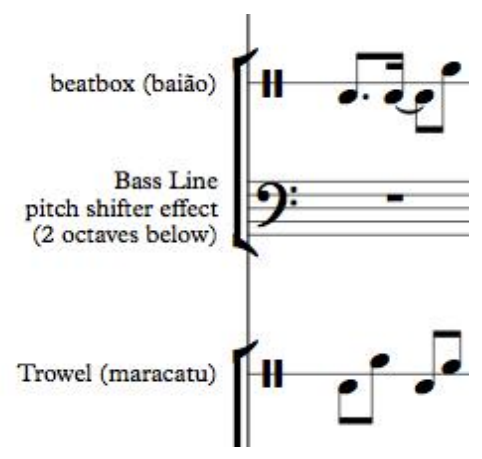

Fonte: transcrição do autor a partir de performance apresentada igualmente pelo autor, 2017.

$\mathrm{Na}$ sequência há a criação de duas linhas melódicas sobrepostas que assumem função harmônica. A primeira linha é composta por três vozes paralelas em intervalos de terça. A segunda é composta por 2 vozes, também paralelas e em terças, porém com notas longas e em registro mais grave. Essa linha é realizada com efeito de oitava abaixo para simular uma flauta contralto.

Por fim, há uma linha de baixo, realizada com efeito de duas oitavas abaixo, simulando uma flauta baixo com octaver (efeito de oitava abaixo). Esta linha é, na verdade, um arpejo no ritmo do 
ostinato em baião (beatboxer) gravado na Pista 01.

FIGURA 4 - Detalhe para ostinatos em ritmo de baião (beatbox e flauta baixo).

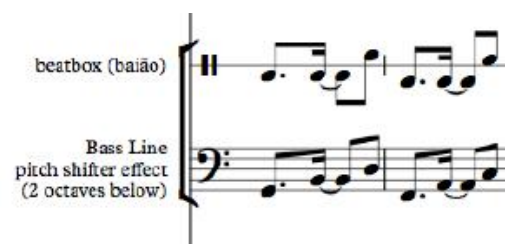

Fonte: transcrição do autor a partir de performance apresentada igualmente pelo autor, 2017.

FIGURA 5 - Sequência de construção da Estrutura Sonora Base.

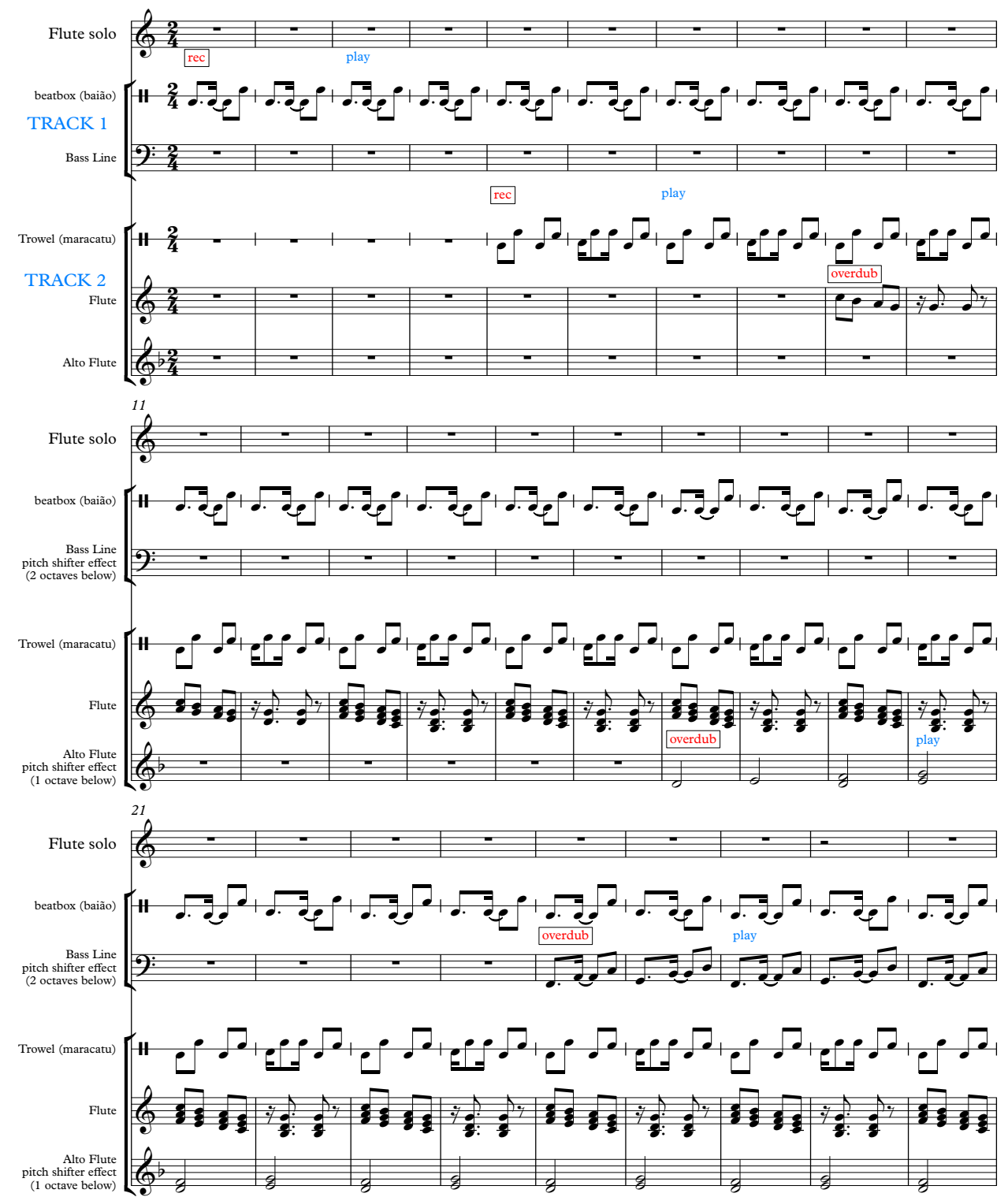

Fonte: transcrição do autor a partir de performance apresentada igualmente pelo autor, 2017. 


\section{Momento 02}

Após concluir a construção da Estrutura Sonora Base, executa-se uma variação da melodia Beat 70. O que chamo aqui de "variação" diz respeito à adequação da melodia à Estrutura Sonora Base. Pelo fato dessa ser diferente do original em termos rítmicos, há uma espécie de “contração" do número de compassos para se tocar a melodia. Neste sentido, há alterações nas células rítmicas e até mesmo das próprias alturas em relação à melodia original.

FIGURA 6 - Melodia de Beat 70 (Pat Metheny).

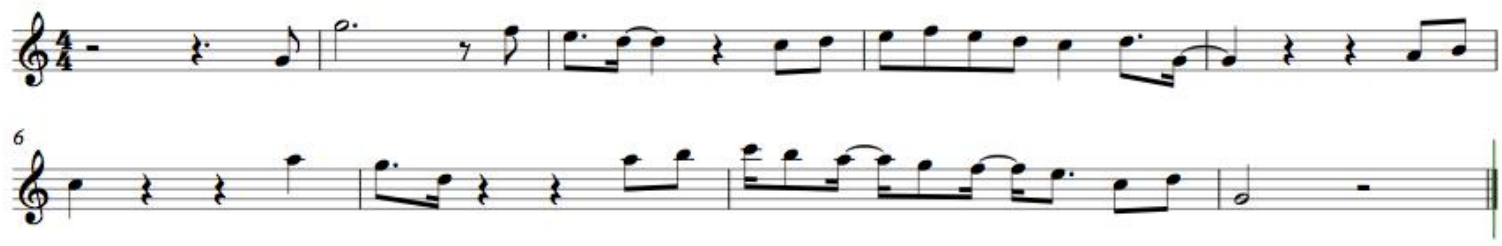

Fonte: transcrição do autor a partir de performance apresentada por Michele Gori, 2017.

FIGURA 7 - "Variação" de Beat 70 (Pat Metheny) adaptada à Estrutura Sonora Base.

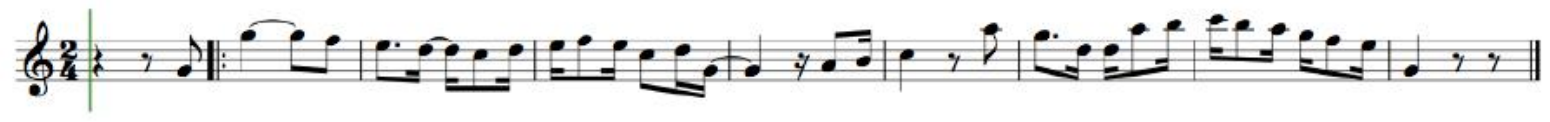

Fonte: transcrição do autor a partir de performance apresentada pelo autor, 2017.

Como a base encontra-se em compasso binário e com ritmos tipicamente brasileiros como groove, a melodia assume um “sotaque” distinto. Nesta secção aplica-se um efeito de rotary e o delay na flauta de forma a fazer uma alusão ao timbre utilizado por Michele Gori em seu arranjo. $\mathrm{O}$ flautista aplicou o feito chorus juntamente com um delay a partir do software Guitar Rig. O efeito chorus tem por característica adicionar um som levemente desafinado ao som original para acrescentar profundidade e ambiência. No meu caso, optei por utilizar o efeito rotary (velocidade fast) que reproduz o efeito como o som de um alto falante rotativo, modulando o timbre da flauta, também misturado com um delay. 


\section{Momento 03}

Aqui executa-se uma “ponte”, uma articulação entre os dois temas musicais, de forma a gerar variação na dinâmica e densidade sonora. Para tal, muta-se a Pista 01 (continua a ser tocada a Pista 02). Esta ponte também está notada e a flauta fica em silêncio, ou seja, apenas é reproduzido nos amplificadores a base sonora gravada na Pista 01. Portanto, a variação trata-se do parâmetro da densidade (que nesse momento fica reduzida) e na pausa do som tocado em tempo real. Durante esse momento muda-se o efeito do pedal GP-10 para executar o próximo momento.

FIGURA 8 - "Ponte” com redução de densidade da massa sonora.

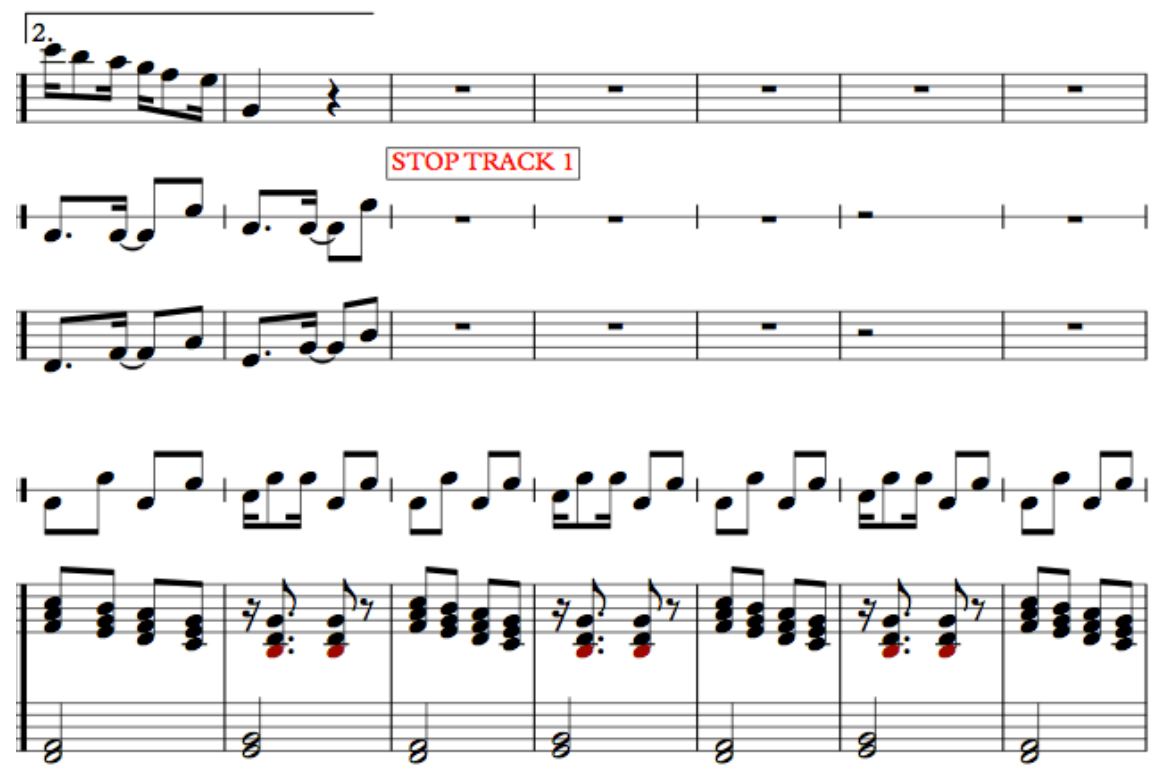

Fonte: transcrição do autor a partir de performance apresentada pelo autor, 2017.

\section{Momento 04}

$\mathrm{Na}$ sequência, toca-se uma variação da melodia Asa Branca (Luiz Gonzaga/Humberto Teixeira), nos mesmos moldes do momento 02. Aqui também ocorre alteração na melodia original para adequar-se à Estrutura Sonora Base. Portanto, tanto as células rítmicas são alteradas como também as próprias alturas, ou seja, as notas da melodia. 


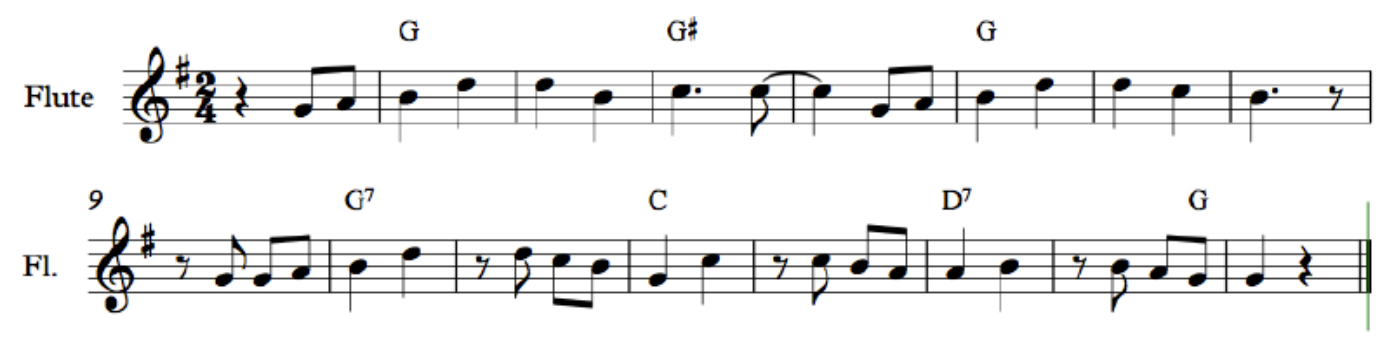

Fonte: transcrição do autor.

FIGURA 10 - Variação” de Asa Branca (Luiz Gonzaga/Humberto Teixeira).
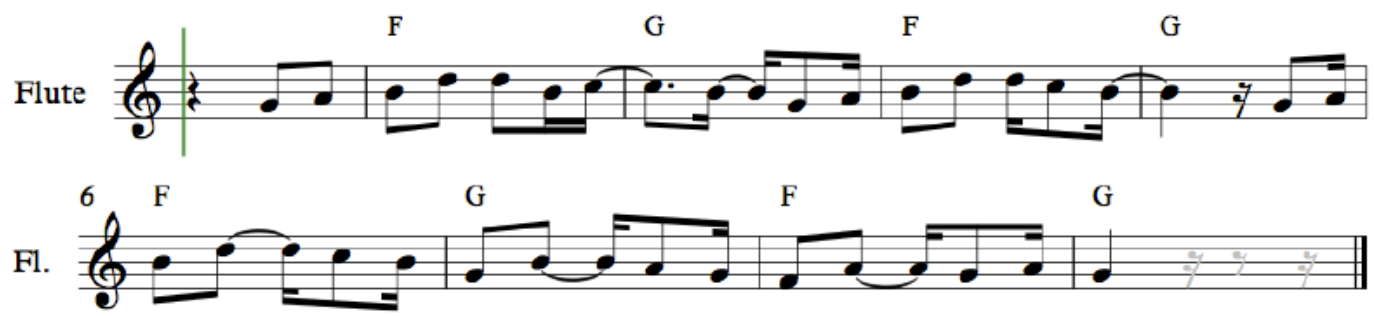

Fonte: transcrição do autor.

Nesta secção aplica-se o efeito harmonist para soar uma segunda voz em quarta paralela descendente, fazendo alusão aos duetos de pífaro do Nordeste brasileiro (apesar de geralmente tocarem em intervalos de terças, às vezes tocam em intervalos de quarta $)^{11}$. A ideia aqui não é fazer uma reprodução na íntegra, mas apenas uma "citação".

\section{Momento 05}

Coda final. Aqui muta-se a Pista 01 e, depois de oito compassos, muta-se a Pista 02 finalizando a performance. Nesta secção a flauta fica livre para improvisar sobre a Estrutura Sonora Base. O acionamento do pedal, para finalizar a performance, dá-se de forma abrupta. Esse ataque

\footnotetext{
${ }^{11}$ Sobre Banda de pífaro de Caruaru, conferir a dissertação de Mestrado de Carlos Pedrasse (2002). Disponível em: <http://repositorio.unicamp.br/jspui/handle/REPOSIP/284904 >. Acesso em: 03 out. 2019.
} 
dá-se após o tempo 2 do compasso, criando sensação de suspensão e surpresa. Assim, o pedal deve ser pressionado na segunda metade do segundo tempo, visto que as notas tocadas na primeira metade deste (reproduzidas pela LS), devem ser ouvidas e, depois disso, finalizar.

Em alternativa, entre as secções 3 e 4 ou entre 4 e 5, é possível realizar uma secção de improvisação livre utilizando uma escala de acorde dominante - Sol Mixolídio - (com opção de notas outside, numa linguagem jazzística), interagindo com a estrutura total composta pelas duas pistas ou mesmo mutando uma delas de forma igualmente livre ${ }^{12}$.

FIGURA 11 - Finalização após ataque do segundo tempo do compasso.

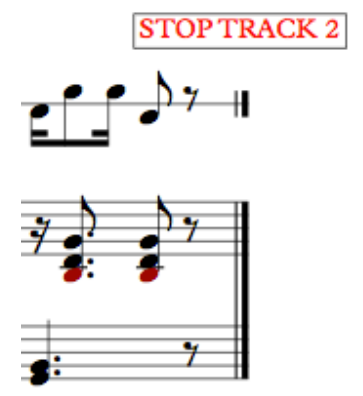

Fonte: transcrição do autor a partir de performance apresentada pelo autor, 2017.

\section{A relação do corpo frente ao uso da Loop Station}

De modo geral, incorporar a LS ao Setup de um instrumento resulta numa expansão das potencialidades de uso do corpo e, consequentemente, uma maior exigência pela perspectiva interpretativa. Movimentos deverão ser realizados com os pés, algumas vezes de forma consecutiva e em dispositivos diferentes, o que poderá implicar numa dificuldade a ser enfrentada. Assim, o intérprete vê-se confrontado com um desafio e terá que decidir se permitirá que esta tarefa diminua suas competências na performance ou se, pelo contrário, procurará usar estes novos movimentos a seu favor, incorporando-os à performance, ou seja, fazendo deles mesmos um ato performativo.

\footnotetext{
${ }^{12}$ Como já referido, neste caso foi priorizada a questão da curta duração da performance em função da limitação de tempo relativamente ao contexto de Comunicação em Congresso.
} 
Nesse sentido, em termos de conceptualização, a partir das noções de “espaço” propostas por Laban (1978: 170), o percussionista Fernando Chaib (2012: 97, 98) desenvolve uma linha precisa de argumentação que categoriza como "gesto intelectual” e que tem se demonstrado uma pertinente ferramenta teórica de orientação para os estudos práticos do performer. Segundo Chaib

\begin{abstract}
O autor [Laban, 1978: 170] sugere a existência de quatro fases do esforço mental que precedem e acompanham ações propositadas, sendo elas: atenção, intenção, decisão e precisão. O movimento relativo ao espaço encaixa-se na fase de atenção. A tendência será o performer buscar uma auto orientação criando uma relação com um objeto de interesse de modo direto e imediato ou de forma prudente e volúvel. A intenção determinará a tensão muscular depositada sobre a ação, graus de força, variando entre o leve e o pesado. A decisão é talvez o momento mais intuitivo de toda a ação pois refere-se ao tipo de gesto realizado (por exemplo de que maneira o performer deverá estender ou não o braço, se faz ou não sentido naquele exato momento o movimento pensado). A precisão será o fator que antecede brevemente á ação objetiva. O controle das outras fases será determinante para que esse fator se relacione ao movimento de forma congruente à execução da ação pensada. Precisão será o próprio domínio do movimento bem estudado (CHAIB, 2012, p. 97, 98).
\end{abstract}

Neste sentido, em relação à primeira fase (atenção), o estudo aplicado para desenvolver a performance consistiu em analisar os movimentos necessários a se realizar com os pés nos 3 dispositivos utilizados (LS, GP-10 e Footswitch), de forma a compreendê-los e, consequentemente, interiorizá-los. Para isso foi importante fazer um reconhecimento do espaço envolvido e dos gestos adequados à performance. Alguns fatores são importantes a se considerar em relação aos diferentes tipos de dispositivos LS e que interferem no mecanismo de execução dos movimentos. Isso tem a ver, por exemplo, com o perfil dos chassis dos pedais. No caso do modelo Boss RC-30, por exemplo, trata-se de um pedal tipo twin, com dois botóes (rec/play e stop) com dimensões e distância entre ambos relativamente confortável. No caso do pedal Boss RC-300, com chassi diferente (dimensôes bem maiores), os mesmos botões são bem menores e muito mais próximos um do outro, o que dificulta a execução além de colocar o performer numa situação muito maior de risco, visto que fica muito suscetível a carregar no botão ao lado de forma equivocada.

Outro ponto a se considerar é a opção entre se tocar sentado ou em pé. Tocar sentado permite utilizar os dois pés com maior precisão em relação aos pedais. Contudo, pode não ser tão confortável para trocar de instrumento durante a performance ou provocar ruído pela cadeira ao se deslocar. Por outro lado, tocar em pé (que foi a opção adotada), requer maior destreza de equilíbrio para os 
movimentos com os pedais.

Outro aspecto importante diz respeito ao tipo de microfone utilizado. No caso da flauta, o ideal seria utilizar um microfone tipo "de cabeça” para poder ter liberdade para olhar para baixo e ter maior visualização dos pedais. No meu caso, por utilizar um microfone de mão preso a um pedestal, criou-se uma dificuldade a mais visto que, ao se tocar a flauta, forçosamente é preciso olhar para frente para conseguir captar o som pelo microfone, o que dificulta a visualização dos pedais. Assim, foi preciso criar um senso de direção dos pés sem olhar para baixo, pelo menos em alguns momentos.

Outra questão é a familiarização com o uso de auscultadores (fones de ouvido). Nesse caso, não foi utilizado o click (metrônomo), porém, quando se opta por utilizar, há que se verificar o volume regulado de forma a não vazar para o microfone. Esta situação é comum ao trabalho realizado em estúdio, o que reforça a ideia de abordar a LS como um “estúdio portátil”.

Em relação à fase 2 (intenção), foi necessário desenvolver um senso de tensão e força exercida pelos pés nos dispositivos. Isso porque, ao acionar os pedais, provoca-se um ruído que pode ser captado pelo microfone e ser incorporado ao loop. Como isso não era desejável, foi preciso trabalhar esta componente.

Outro aspecto importante aqui diz respeito ao equilíbrio de volumes entre os loops e o som em tempo real. Como as camadas da Estrutura Sonora Base são densas, e portanto com grande volume de som, foi preciso desenvolver um senso de dinâmica no momento da construção dessas camadas. Nesse caso, as linhas melódicas gravadas foram executadas intencionalmente um pouco mais piano. Vale aqui ressaltar que, neste tipo de performance, as colunas de amplificação funcionam como "instrumento musical”, segundo Jos Muldor (2010: 13), e como tal é preciso estar em equilíbrio com o som tocado em tempo real.

A fase 3 (decisão), diz respeito ao lado intuitivo de toda a ação. Aqui foi necessário desenvolver um senso interno de ritmo para que o corpo busque movimentar-se dentro do fluxo do groove do arranjo/exercício a ser tocado. Pressionar os pedais dentro do "balanço" possibilitou localizar-se dentro do compasso, ao passo que um movimento sem consciência rítmica provocava incerteza quanto à sinergia almejada e mesmo desconforto em termos de equilíbrio para a movimentação necessária. A precisão do acionamento dos pedais para realizar o início e o 
fechamento do primeiro loop requer um treino especial, visto que se este não for definido, os overdubs ficarão todos comprometidos.

Por fim, a fase 4 (precisão), refere-se ao domínio do gesto bem estudado. Assim, como consequência das açóes desenvolvidas nas fases anteriores, anotaçóes e mapeamento dos movimentos dos pés, troca de efeitos, troca de instrumentos e equilíbrio de volumes entre o som tocado em tempo real e o som reproduzido pelas caixas amplificadas, foi possível alcançar um resultado sonoro desejado.

\section{Reflexões e conclusões}

No início deste artigo foi apontado que este trabalho foi elaborado com fins didáticos, por isso chamá-lo de "arranjo/exercício". Tenho-o usado em oficinas e considero que o resultado tem sido eficaz pois otimiza o tempo para aqueles que, por não terem experiência com a máquina, ficam sem ideia do que tocar e, muito menos, de como operar a sequência de acionamento dos pedais.

Dito isto, vale voltar à problemática apresentada como ponto de partida neste texto: a LS é uma ferramenta ampliadora ou limitadora de possibilidades? A partir das ponderaçóes apontadas ao longo do texto, dos exemplos descritos em partitura e do áudio com o resultado sonoro obtido, pode-se concluir que há várias questóes a se considerar no que diz respeito à perspectiva estética do produto musical que se pode criar com o uso da LS.

No caso do exemplo aqui apresentado, entendemos que alguns aspectos foram adotados no sentido de valorizar o resultado sonoro almejado: 1) exploração de diferentes timbres a partir de a) aplicação de efeitos e modulação do som na flauta transversal (pelo pedal GP-10); b) efeitos de ritmo para construção do groove (beatboxer e colher de pedreiro); 2) construção da Estrutura Sonora Base dividida em duas pistas distintas a fim de criar ponte entre secções.

Uma vez que a opção de uso da LS foi feita, primou-se por otimizar a sinergia do performer para com os dispositivos operados pelos pés. Como já mencionado, a partir do conceito de "gesto intelectual", foi adotada uma rotina de estudos de forma a incorporar os movimentos do corpo à performance.

Concluindo, entendemos que este trabalho oferece, sobretudo aos intérpretes com pouca 
experiência em uso de dispositivos eletrônicos, alguns contributos, quer do ponto de visto artístico, quer do ponto de vista crítico. Além disso, a experiência a partir dos trabalhos realizados no LoopLab tem demonstrado que, para além da possibilidade de exploração da LS no âmbito da performance musical, é possível utilizá-la no âmbito da educação e mesmo dos estudos individuais, como em exercício de estudos de escalas, improvisação, métricas de compasso, etc. Portanto, tais possibilidades de uso desta ferramenta poderão ser exploradas e disponíveis ao público de forma a contribuir para o conhecimento científico produzido acerca desta temática.

\section{AGRADECIMENTOS}

À FCT - Fundação para a Ciência e Tecnologia/PT - entidade financiadora deste projeto de pesquisa em âmbito de bolsa de pós-doutoramento. Ao INET-md - Instituto de Etnomusicologia, centro de estudos em música e dança - pelo apoio institucional. À Professora Doutora Susana Sardo pela orientação desta pesquisa.

\section{REFERÊNCIAS}

BARBOSA, Jerônimo; WANDERLEY, Marcelo M; HUOT, Stéphane. Exploring playfulness in Nime design: the case of live looping tools. NIME, 2017. Disponível em: <http://homes.create.aau.dk/dano/nime17/papers/0018/index.html>. Acesso em 01 jul. 2019.

CHAIB, Fernando. O Gesto na Performance em percussão: Uma abordagem Sensorial e Performativa. Tese (Doutorado), Departamento de Comunicação e Arte/DECA, Universidade de Aveiro. Aveiro, 2012. Disponível em: <https://ria.ua.pt/handle/10773/9880>. Acesso em 01 jul. 2019.

LABAN, R. 1978. Domínio do Movimento. Traduzido por A. M. B. DE VECHI e M. S. M. NETTO. 5a ed. São Paulo: Summus Editorial. Edição original, Mcdonald \& Evans Limited, 1971. MARCHINI, Marco; PACHET, François; and CARRÉ, Benoît. Rethinking reflexive looper for structured pop music. NIME, 2017. Disponível em:

<https://www.nime.org/proceedings/2017/nime2017_paper0027.pdf>. Acesso em: 01 jul. 2019.

MULDOR, J. The loudspeaker as musical instrument. In Proceedings of the 2010 Conference on new interfaces for musical expression (NIME, 2010). P.: 13-18. Sidney, Austrália. Disponível em: <https://www.nime.org/proceedings/2010/nime2010_013.pdf>. Acesso em: 01 jul. 2019. 
PACHET, François; ROY, Pierre; MOREIRA, Julian; and D'INVERNO, Mark. Reflexive loopers for solo musical improvisation. In Proceedings of the sigchi conference on human factors in computing systems (chi '13). ACM, New York, NY, USA, 2013. (2205-2208)

DOI=http://dx.doi.org/10.1145/2470654.2481303. Disponível em:

<http://dl.acm.org/citation.cfm?doid=2470654.2481303>. Acesso em: 01 jul. 2019.

PAIVA, J. E. R. Música e Tecnologia, do vinil ao mp3. Contemporânea (UFBA. Online), v. 10, p. 99-112, 2012. Disponível em:

$<$ https://portalseer.ufba.br/index.php/contemporaneaposcom/article/view/5796 >. Acesso em: 02 jul. 2019. DOI: http://dx.doi.org/10.9771/1809-9386contemporanea.v10i1.5796.

PEDRASSE, Carlos E. Banda de pífanos de caruaru: Uma análise musical. Dissertação de mestrado. Universidade Estadual de Campinas (UNICAMP). Campinas, 2002. Disponível em: < http://repositorio.unicamp.br/jspui/handle/REPOSIP/284904 >. Acesso em: 02 jul. 2019.

ROCHA, Fernando de Oliveira. Works for percussion and computer-based live electronics: aspects of performance with technology. Dissertação (Doutorado). Schulich School of Music, McGill University, Montreal, Canadá, 2008. Disponível em: < https://repository.asu.edu/attachments/163967/content/Wier_asu_0010E_15461.pdf > . Acesso em: 03 jul. 2019.

SARDO, Susana. Shared Research Practices on and about music: toward decolonizing colonial ethnomusicology. In Josep Martí and Sara Revilla (Org) Making Music, Making Society. Cambridge, Cambridge Scholars, 217-238, 2017.

\section{Trabalhos musicais citados}

GONZAGA, Luís; TEIXEIRA, Humberto. (Compositores). Asa branca . Gravadora Victor, 1947. Suporte: $78 \mathrm{rpm}$.

METHENY, Pat. (Compositor). Beat 70. Geffen Records, 1989. Suporte: CD.

GORI, Michele. Electric Flute Project. Disponível em: http://www.michelegori.it/. Acesso em 01 jul. 2019.

PROKOFIEV, Gabriel. (Compositor). Import/Export. 2008. Disponível em: https://gabrielprokofiev.bandcamp.com/album/import-export-gabriel-prokofiev-suite-for-globaljunk. Acesso em 01 jul. 2019.

MAIER, Florian Magnus. (Compositor). Slipstream. Disponível em: https://www.ntcshop.nl/a-

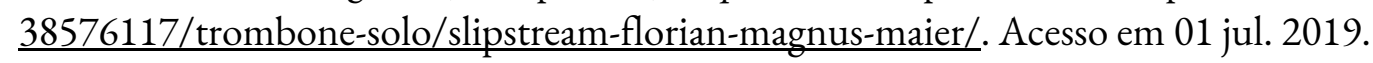


DUARTE, Alexsander Jorge. 0 uso da Loop Station em performance musical: implicações e exigências interpretativas. Revista Vórtex,

\section{SOBRE O AUTOR}

Alexsander Duarte: Suas atividades acadêmicas incluem a produção de concertos, CDs, filmes, artigos, capítulos de livros, partituras e comunicações. É Doutor em Etnomusicologia pela Universidade de Aveiro onde atualmente desenvolve um pós-doutoramento. Integra a equipa de 3 Projetos financiados pela FCT: a) AtlaS: Atlântico Sensível, b) SOMA: Sons e Memórias de Aveiro, c) Xperimus: Experimentação em música na cultura portuguesa. Possui experiência em pedagogia em conservatórios e também regência de bandas de sopro e coral. Além dos seus projetos artísticos a solo, colabora com o tradicional grupo de música portuguesa Toques do Caramulo atuando em países da Europa e África. ORCID: https://orcid.org/0000-0001-9553-802X. E-mail: alex.duarte@ua.pt 


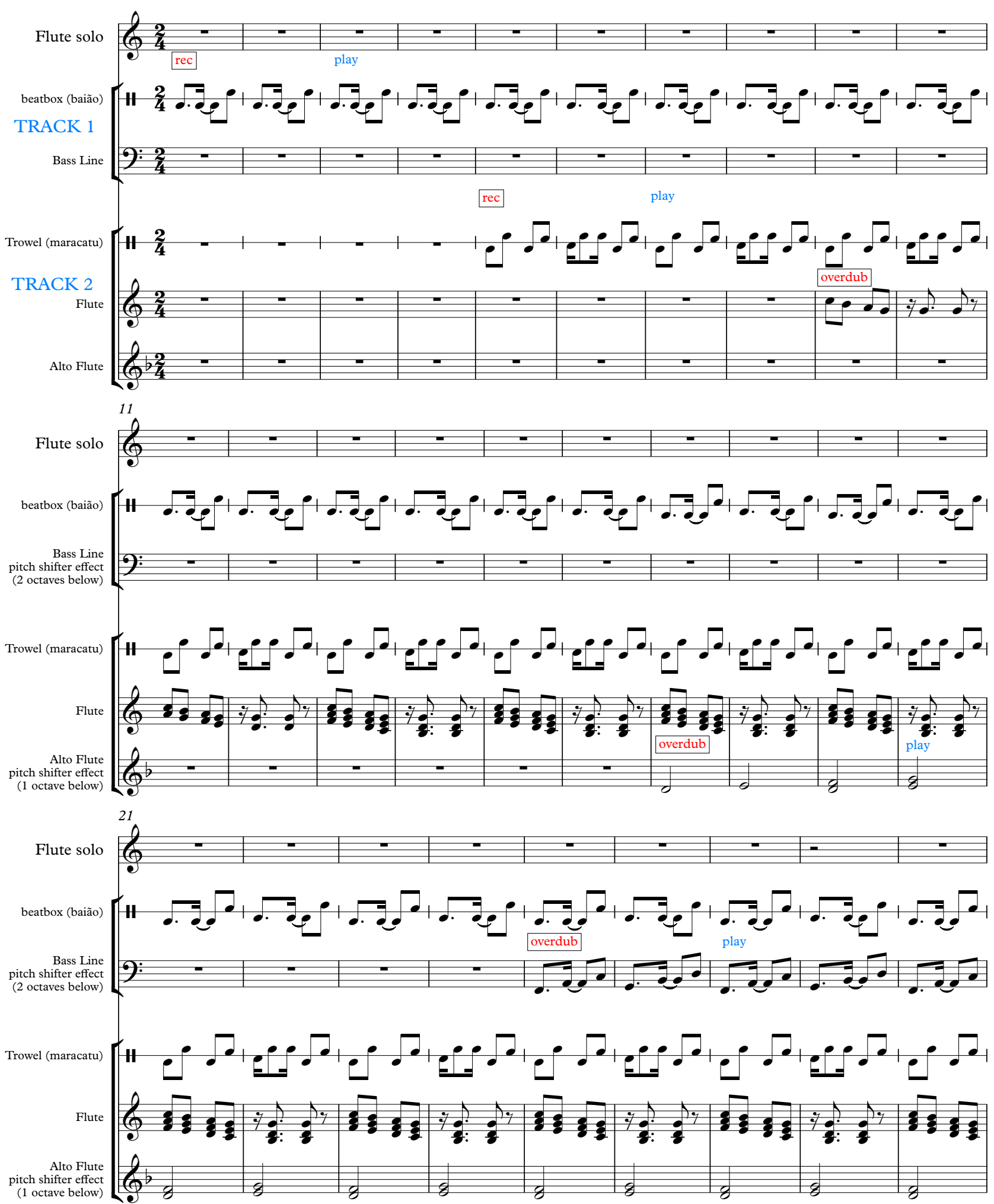



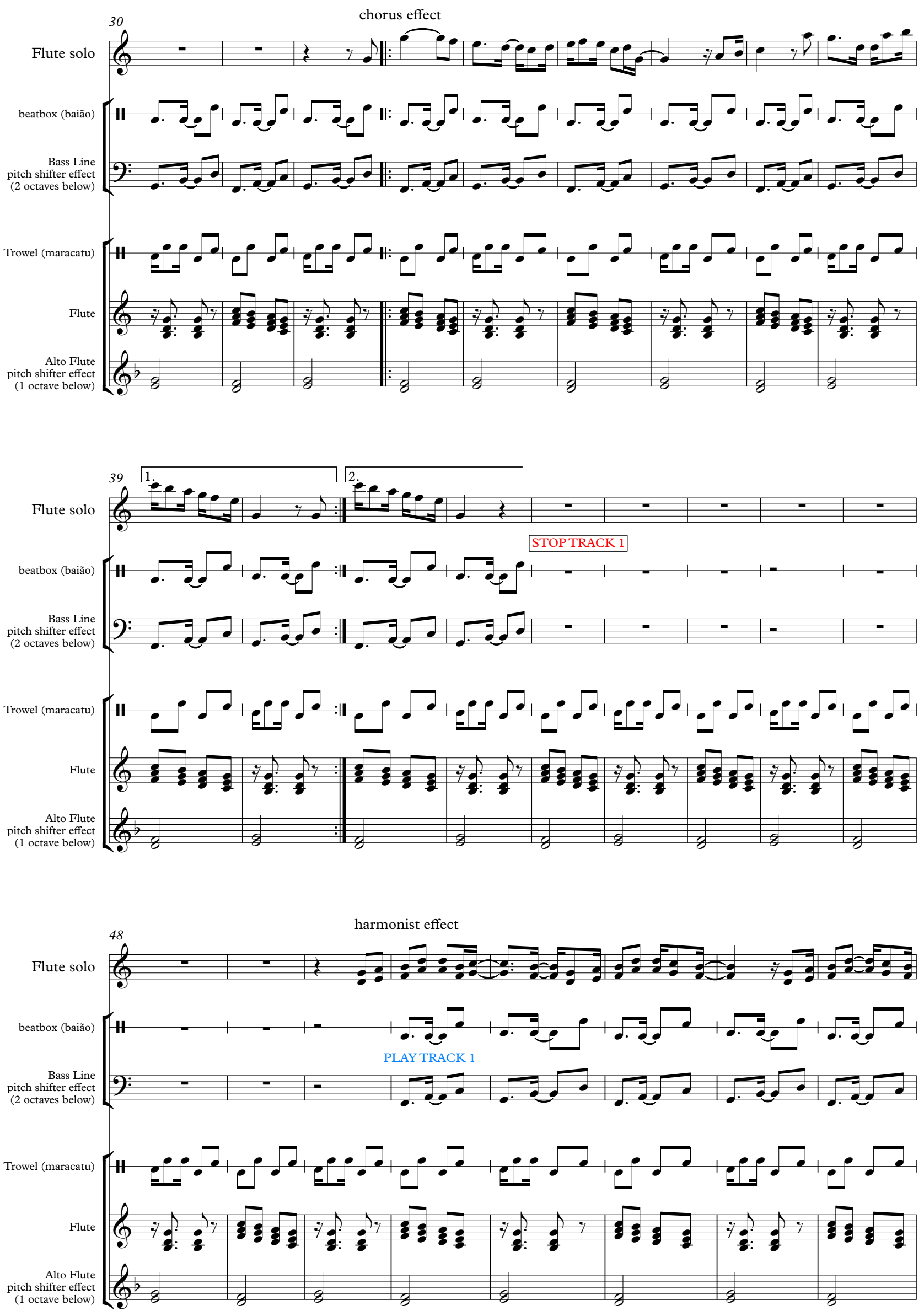


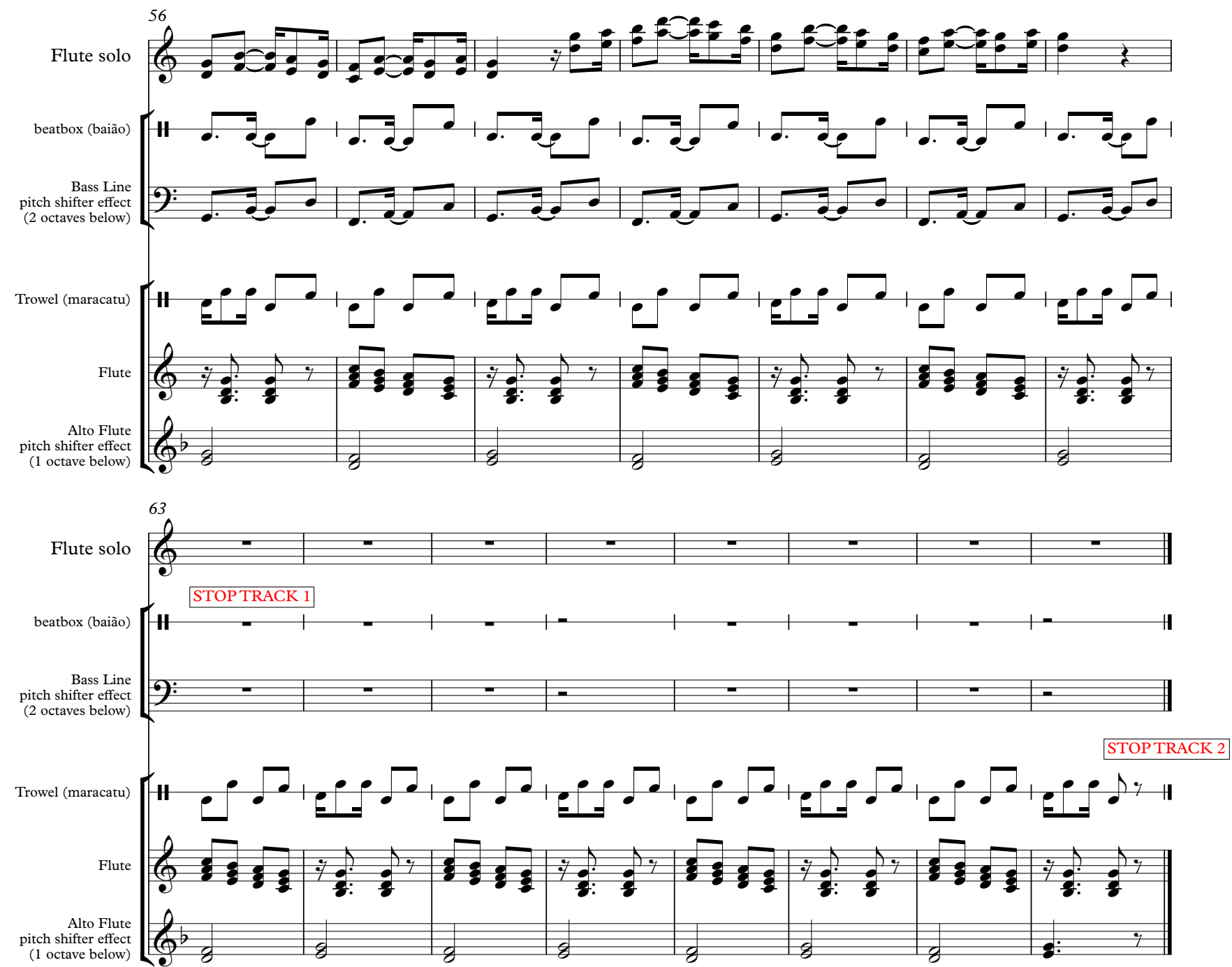

